\section{Rapid and Simple Detection of Porcine Reproductive and Respiratory Syndrome Virus (PRRSV) by Reverse Transcription Loop-Mediated Isothermal Amplification}

\author{
Xi-wen Chen ${ }^{1,2}$, Qian Wang ${ }^{1,3}$, Miao Yin ${ }^{1}$, Zhong-hui Pu ${ }^{1,2}$, Ai-wei Guo ${ }^{3}$, Lian Li ${ }^{1,3}$, \\ Wen-tao Luo ${ }^{1,3}$ and Xiong-qing Wang ${ }^{1, *}$ \\ ${ }^{1}$ Institute of Applied Animal Technology, Mianyang Normal University, Mianyang \\ 621000, China \\ ${ }^{2}$ Research Center of Ecological Agriculture and Animal Husbandry in Northwest \\ Sichuan, Mianyang, 621000, China \\ ${ }^{3}$ College of Life Science, Southwest Forestry University, Kunming, 650224, China
}

\begin{abstract}
A B S T RA C T
Given the economic consequences of infection with porcine reproductive and respiratory syndrome virus (PRRSV) for the global swine industry a rapid and practical early detection assay is required. This study established a reverse transcription-loop-mediated isothermal amplification (RT-LAMP) assay to detect PRRSV. Four primers were designed targeting the ORF5 gene of PRRSV were designed. Reverse transcription and amplification of the viral RNA using AMV reverse transcriptase was optimal at a constant temperature of $65^{\circ} \mathrm{C}$. The output of the RT-LAMP assay was visualized using $1 \%$ agarose gel electrophoresis or color change after the addition of the SYBR Green I dye. The RT-LAMP method was approximately 100 -fold more sensitive than RT-PCR for PRRSV detection. The assay was also specific for PRRSV and did not cross react with CSFV, PCV-2, PPV or PRV. In clinical samples (n=5) RT-PCR and RT-LAMP both identified the same 2 PRRSV infected samples. Thus, the novel RT-LAMP assay described here is a rapid, simple, sensitive, specific test for PRRSV that can potentially be applied in clinical settings.
\end{abstract}

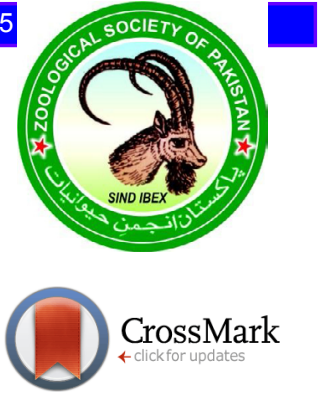

Article Informatio

Received 23 May 2018

Revised 26 June 2018

Accepted 28 July 2018

Available online 04 August 2018

Authors' Contribution

XC and QW carried out most of

the experiments and wrote the

manuscript. XW, AG and ZP critically

revised the manuscript and the

experimental design. MY, LL and WL

helped with the experiments.

Key words

Reverse transcription loop-mediated isothermal amplification (RT-LAMP)

Porcine reproductive and respiratory

syndrome virus (PRRSV), Rapid

detection.

\section{INTRODUCTION}

$\mathrm{P}$ orcine reproductive and respiratory syndrome virus (PRRSV) is a member of the genus Arterivirus within the family Arteriviridae, which also includes equine arteritis virus (EAV), murine lactate dehydrogenaseelevating virus (LDV), and simian hemorrhagic fever virus (SHFV) (Cavanagh, 1997; Snijder and Meulenberg, 1998). PRRSV is a positive-sense, single-stranded RNA virus that contains an approximately $15 \mathrm{~Kb}$ genome with nine open reading frames (ORFs) termed ORF1a, ORF1b, ORF2a, ORF2b, ORF3, ORF4, ORF5, ORF6, and ORF7. PRRSV infection was first documented in the United States in acute virus infection in 1987 (Bilodeau et al., 1991). Since that time PRRSV has been reported in other countries and has caused substantial economic losses in the global swine industry. In the United States alone the costs of PRRSV are estimated to reach $\$ 560$ million (Cho and Dee, 2006;

\footnotetext{
* Corresponding author: wang xq193@163.com 0030-9923/2018/0005-1799 \$ 9.00/0

Copyright 2018 Zoological Society of Pakistan
}

Beura et al., 2011). In China, highly pathogenic strains of PRRSV began to emerge in the spring of 2006 that have been costly to the Chinese swine industry (Fang et al., 2007; Li et al., 2007; Tian et al., 2007). There are no effective treatments for PRRSV and control measures often fail. Therefore, early detection and identification of PRRSV plays an important role in controlling the spread of the disease.

Currently, some laboratory techniques such as serological, molecular biology and immunology are utilized to confirm or eliminate PRRSV infection. Because of the high specificity and sensitivity, reverse transcriptase polymerase chain reaction (RT-PCR) was widely utilized in laboratories. However, these methods require certain equipment, expensive reagents and highly trained operators (Maruyama et al., 2003). It is less economical and practical at the grassroots level. It is necessary to develop a rapid, sensitive, specific and simple detection method.

Loop-mediated isothermal amplification method (LAMP) is a rapid, highly sensitive, specific, simple, low cost assay that might be an alternative to traditional PRRSV detection assays (Notomi et al., 2000). This method has 
already been widely used to detect numerous viruses, bacteria, parasites, and fungi (Zhao et al., 2010; Malele et al., 2013; Song et al., 2014). Specificity is ensured by four primers that recognize six specific regions of the target genes. The visual read out is apparent to the naked eye and is based on the SYBR Green I or visualized by agarose gel electrophoresis (Njiru, 2012). The purpose of this study was to develop an RT-LAMP assay for rapid detection of PRRSV infection.

\section{MATERIALS AND METHODS}

\section{DNA and RNA extraction}

Total DNA and RNA were extracted from the feces and, internal organs of PRRSV infected and uninfected pigs using the MiniBEST Viral RNA/DNA Extraction Kit Ver. 5.0 (TaKaRa, Dalian, China) according to the manufacturer's specification. DNA and RNA were stored at $-20^{\circ} \mathrm{C}$ until it was used for experiments.

\section{RT-LAMP primer design}

In order to ensure the specificity of the test, two set of primers were designed targeting the ORF5 gene. The sets forward and backward outer primers (F3 and B3) and forward and backward inner primers (FIP and BIP) were designed based on the sequences published in GenBank using the online program Primer Explorer version 4.0 software (http://primerexplorer.jp/e/index.html). The RTLAMP primer sequences are shown in Table I. Primers were synthesized by Beijing Genomics Institute.

\section{Empirical optimization of the RT-LAMP reaction}

To ensure the most accurate assay, the time and temperature of the RT-LAMP reactions were empirically optimized. The RT-LAMP reactions were carried out on ice in sterile tubes. The $25 \mu \mathrm{L}$ reaction mixture contained 1 $\times$ ThermoPol buffer (New England Bio-labs, USA), $6 \mathrm{mM}$ $\mathrm{MgSO}_{4}$ (New England Bio-labs, USA), $1.4 \mathrm{mM}$ dNTPs (TaKaRa, Dalian, China), $0.2 \mu \mathrm{M}$ each outer primer (F3 and B3), 1.6 $\mu \mathrm{M}$ each inner primer (FIP and BIP), 2.5U of AMV reverse transcriptase (TaKaRa, Dalian, China), $\mathrm{ddH}_{2} \mathrm{O}$, and 500ng of RNA template. The reaction mixture was incubated in a $95^{\circ} \mathrm{C}$ water bath $5 \mathrm{~min}$ and then quickly cooled on ice before the enzyme mix was added. After adding the enzymes, the reactions were incubated in a water bath kept at $59,61,63,65$, or $67^{\circ} \mathrm{C}$ for $10 \mathrm{~min}$ to determine the optimal reaction temperature. The reaction was then terminated by incubating at $80^{\circ} \mathrm{C}$ for $2 \mathrm{~min}$. To determine the optimal time, the reactions were allowed to proceed for $45,50,55,60$, or $65 \mathrm{~min}$.

\section{Specificity of LAMP detection}

The specificity of the new assay was determined using RNA extracted from PRRSV and CSFV infected pigs and DNA extracted from PCV-2, PPV, and PRV infected pigs. The assay products were analyzed by $1 \%$ agarose gel electrophoresis and monitored by color change in the reaction tube when SYBR Green I dye was added to the reaction.

\section{Sensitivity of LAMP detection}

Total RNA was extracted from the feces and internal organs of PRRSV infected pigs. The RNA was prepared as described in section 2.1 and brought to a final concentration of $10 \mathrm{ng} / \mu \mathrm{L}$. A 10 -fold serial dilution series was mades frome the sample (final concentration range: $10^{-1}-10^{-5} \mathrm{ng} /$ $\mu \mathrm{L})$ and used as the templates for the RT-LAMP assay. The sensitivity of the RT-LAMP assay was compared to RTPCR.

\section{RESULTS}

\section{The RT-LAMP method successfully detected PRRSV}

To determie whether the RT-LAMP reaction was detecting PRRSV, a positive control template was amplified using RT-LAMP and RT-PCR. The output of the RT-LAMP assay was visualized by both $1 \%$ gel electrophoresis under ultraviolet light and visual color change. By gel electrophoresis, RT-LAMP amplification of the positive control template produced a ladder of multiple hands, and there were no bands in the negative control (Fig. 1A). Similarly, only the positive control templated changed color from orange to green when the SYBR Green I dye was added (Fig. 1B). The presence of PRRSV in the positive control, and its absence in the negative control, was confirmed by RT-PCR (Fig. 1C).

Table I.- Primer sequences used for the RT-LAMP assay.

\begin{tabular}{llc}
\hline Primer name & Sequences (5'-3') & Nucleotide position $^{\mathbf{a}}$ \\
\hline F3 & CCCGTGTTGACTCACATTGT & $217-236$ \\
B3 & AGAGTAGCGCCAGGACAT & $400-417$ \\
FIP (F1c+F2) & CCGTGATAATATCCGGCGGTGG-CTCACCACCAGCCATTTCC & F1c:296-317 F2:250-268 \\
BIP (B1c+B2) & TTACGCAGTCTGTGCTCTGGC-GCAGTTCTTCGCAAGCCTAA & B1c:339-359 B2:380-399 \\
\hline
\end{tabular}

aSequence positions are for the TJM strain of PRRSV in the ORF5 gene (GenBank accession No. HQ679913). 

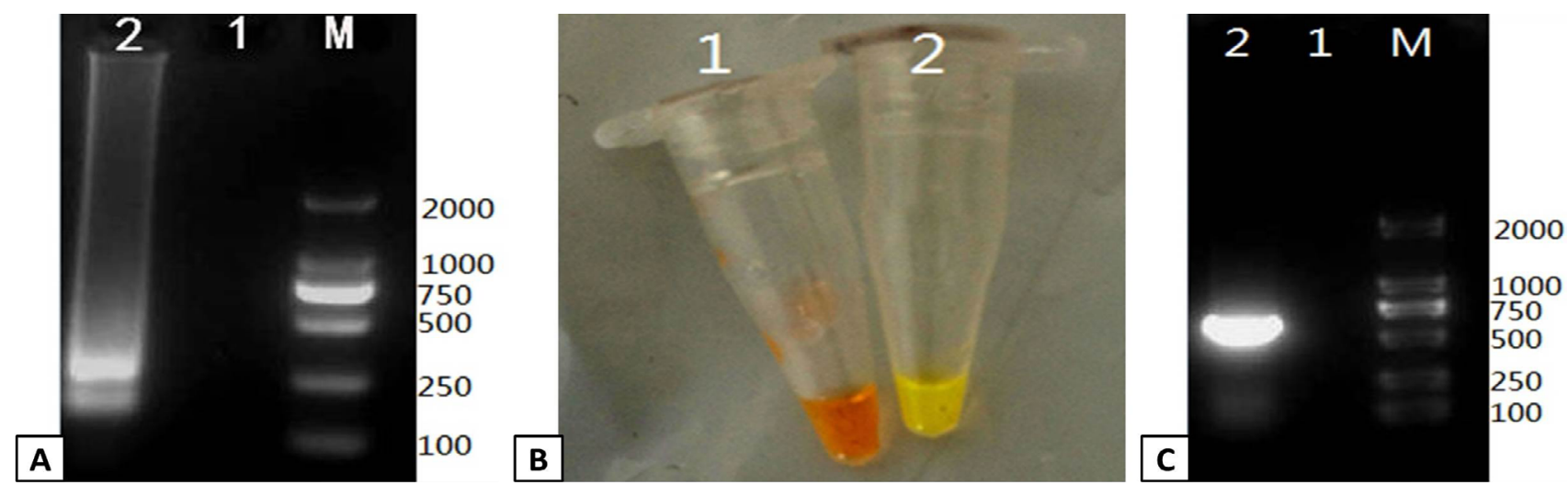

Fig. 1. Verification of the PRRSV RT-LAMP assay. RT-LAMP was used to amplify a positive control template and compared to a negative control. The output of the RT-LAMP assay was monitored by gel electrophoresis and color change. (A) $1 \%$ agarose gel electrophoresis of the RT-LAMP products. Lanes: M; DL2000 Marker, 1; negative control, 2; positive control. (B) Color change in the RT-LAMP reaction was monitored followig addition of SYBR Green I dye. Tube 1: negative control, Tube 2: positive control. (C) The positive and negative controls were verified by RT-PCR 1\% agarose gel electrophoresis of the RT-PCR products. Lanes: M; DL2000 Marker, 1; negative control, 2; positive control.
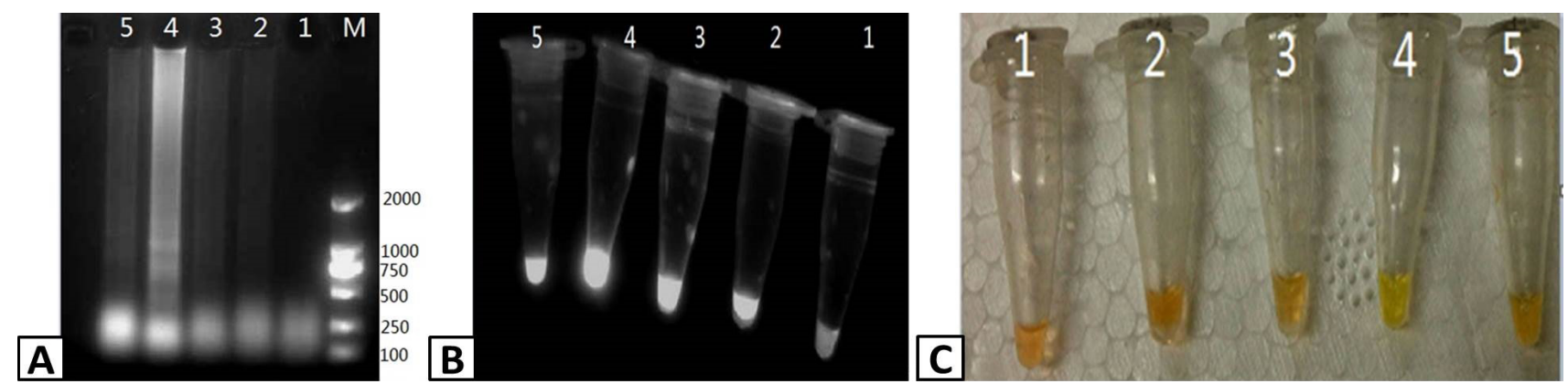

Fig. 2. Optimizing the duration of the RT-LAMP reaction. RT-LAMP was used to amplify PRRSV containing samples. The products of the RT-LAMP reactions were visualized by (A) 1\% agarose gel electrophoresis, (B) UV transillumination, and (C) color change using SYBR Green I dye. Lanes M; DL2000 Marker (A only), 1-5; 45, 50. 55, 60, and 65 min, respectively.

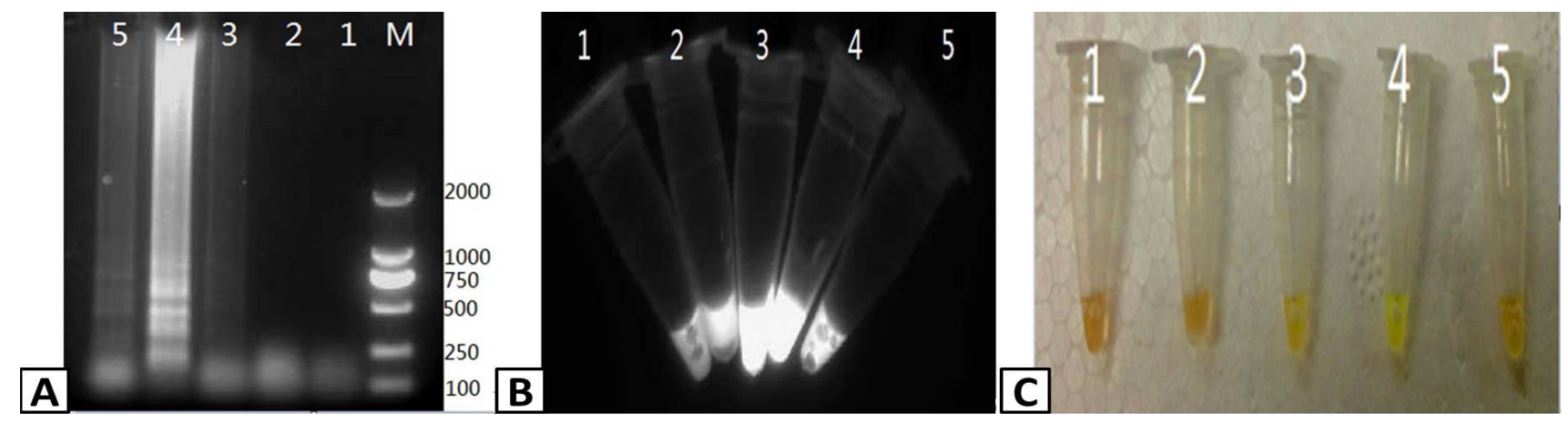

Fig. 3. Optimizing the temperature of the RT-LAMP reaction. RT-LAMP was used to amplify PRRSV containing samples. The products of the RT-LAMP reactions were visualized by (A) $1 \%$ agarose gel electrophoresis. (B) UV transillumination, and (C) color change using SYBR Green I dye. Lanes: M; DL2000 Marker (A only), 1-5; 59, 61, 63, 65, and 67 C, respectively.

\section{Optimization of PRRSV RT-LAMP reaction conditions}

A successful RT-LAMP reaction should produce a ladder of multiple bands which consist of several inverted repeat structures, while an RT-LAMP reaction lacking template should have no bands. To optimize the time of the reaction, RT-LAMP reactions were at $65^{\circ} \mathrm{C}$ for 45,50 , 
55,60 , or $65 \mathrm{~min}$, respectively. No product amplification occurred with a $45 \mathrm{~min}$ reaction time. While product amplification was detected $50-65 \mathrm{~min}$, the peak occurred at $60 \mathrm{~min}$ (Fig. 2). To optimize the RT-LAMP reaction temperature, reactions were carried out at 59,61, 63, 65, or $67^{\circ} \mathrm{C}$ for $60 \mathrm{~min}$. No products were amplified at 59 or $61^{\circ} \mathrm{C}$. The peak product amplification was observed at $65^{\circ} \mathrm{C}$ (Fig. 3). Therefore, the final reaction conditions were a $60 \mathrm{~min}$ incubation period at $65^{\circ} \mathrm{C}$.

\section{Assessing the specificity of the RT-LAMP assay}

Having optimized the reaction conditions, the specificity of the RT-LAMP reaction was tested using primary samples containing PRRSV, CSFV, PCV-2, PPV, or PRV. PRRSV containing samples were the only positive samples (Fig. 4). Indicating that the RT-LAMP assay was specific for PRRSV.
Assessing the sensitivity of the RT-LAMP assay

To determine the sensitivity of PRRSV RT-LAMP, serial 10-fold dilutions of PRRSV RNA were assayed. PRRSV could be clearly detected by RT-LAMP at the $10^{5}$ dilution of the stock template $(10 \mathrm{ng} / \mu \mathrm{L})$, but was only just above the limit of detection in the $10^{3}$ dilution of the stock template (Fig. 5A, C). Detection with RT-LAMP was compared to detection by RT-PCR (Fig. 5B). RT-LAMP was approximately 100-fold more sensitive than RT-PCR.

Application of the RT-LAMP method for diagnosis of PRRSV in serum samples

The optimized RT-LAMP assay was then used to detect PRRSV infection in 5 unknown serum samples. PRRSV infection was confirmed using RT-PCR. Of these samples, 2 were found to contain PRRSV by both RT-PCR and RT-LAMP (Fig. 6), indicating that RT-LAMP is likely suitable for clinical use.
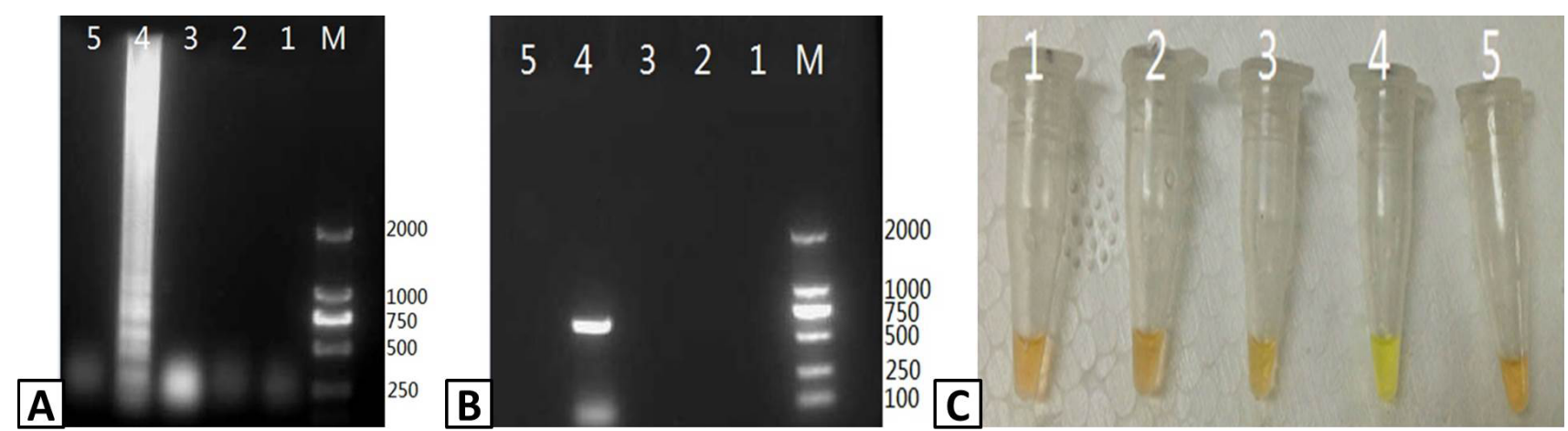

Fig. 4. Assessing the specificity of RT-LAMP for PRRSV. Samples were isolated from pigs infected with PRRSV, CSFV, PCV-2, PPV, and PRV and tested usig the RT-LAMP assay. The output of the assay was visualized using (A) agarose gel electrophoresis and (C) color change with SYBR Green I dye. (B) The presence of PRRSV in the samples was confirmed by RT-PCR and visualized using agarose gel electrophoresis. Lanes: M; DL2000 Marker (A and B only). 1; CSFV, 2; PCV-2, 3; PPV, 4; PRRSV, 5; PRV.
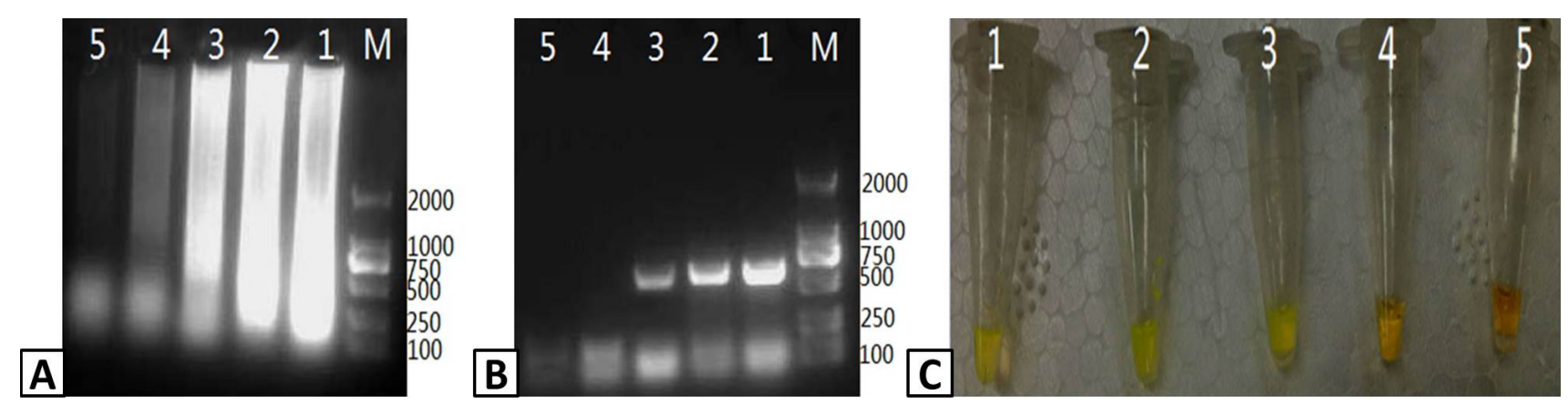

Fig. 5. Assessing the sensitivity of the PRRSV RT-LAMP assay. 10-fold serial dilutions of a stock PRRSV RNA template (10ng/ $\mu \mathrm{L}$ ) were used to assess the sensitivity of the RT-LAMP assay compared to RT-PCR. Output from the RT-LAMP assay was visualized by (A) agarose gel electrophoresis and (C) color change with SYBR Green I dye. (B) RT-PCR amplification of PRRSV

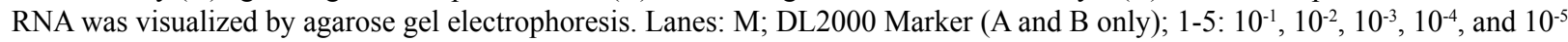
dilutions of the stocktemplate. 


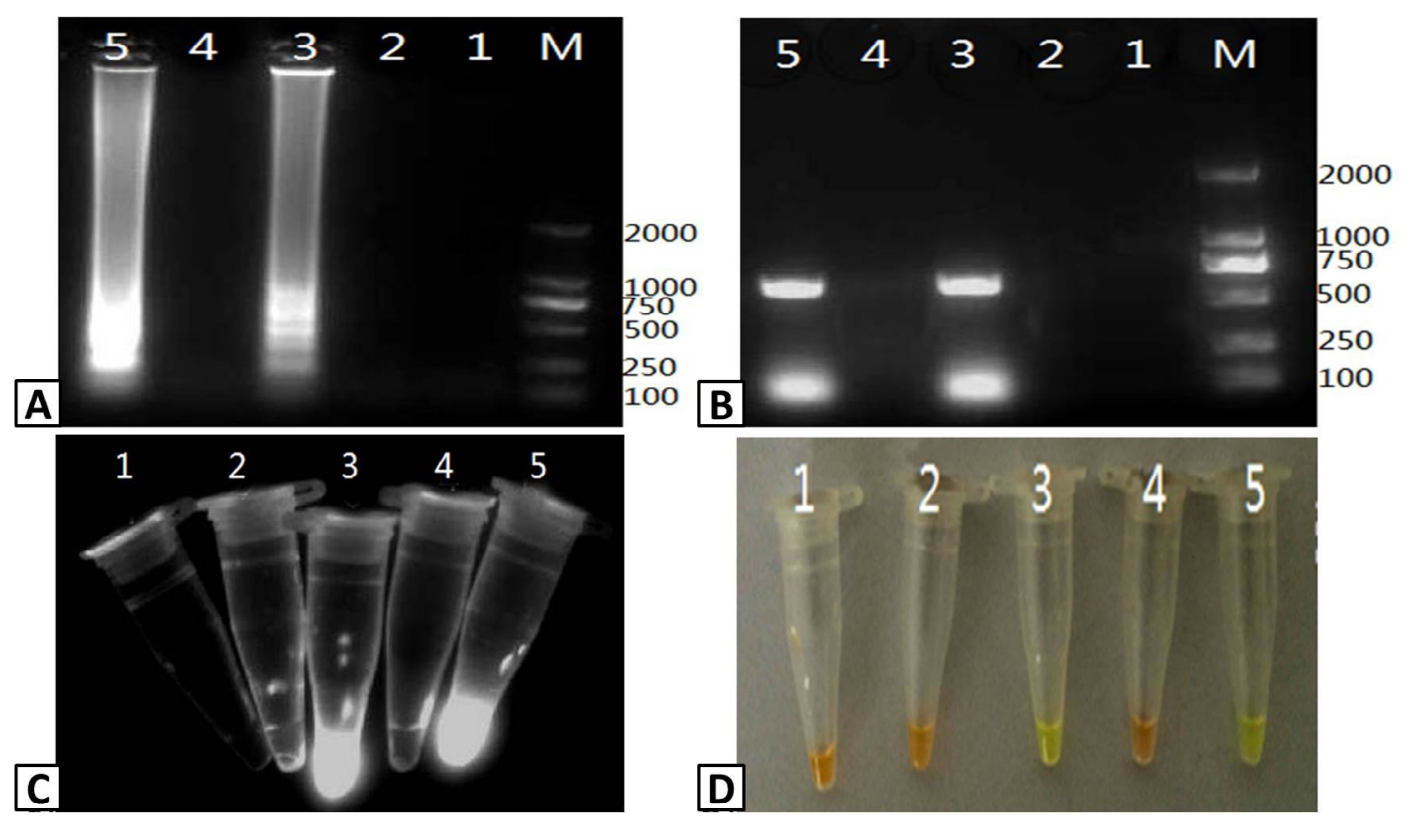

Fig. 6. Detection of PRRSV infection in serum samples. Five (5) serum samples were tested for PRRSV infection using RT-LAMP and RT-PCR. The output of the RT-LAMP assay was visualized using (A) agarose gel electrophoresis, (C) UV transillumination, and (D) color change with SYBR Green I dye. (B) RT-PCR products were visualized using agarose gel electrophoresis of RT-PCR products. Lanes M; DL2000 Marker (A and B only); 1-5; serum samples.

\section{DISCUSSION}

Pork is historically one of the most economically important meat products in China, and infection with PRRSV has become a major concern due to its high infectivity and mortality is sows. However, at present, PRRSV infection is confirmed using techniques such as serology (antibody testing), molecular biology (PCR, in situ hybridization, etc.), and immunodetection assays (immunohistochemistry, immunofluorescence, etc.). These methods are dependent on levels of specific antibody, viral nucleic acids, or viral antigens being above background. For example, the immune peroxidase single-shell test (IPMA) is available to detect PRRSV specific serum antibodies using a virus neutralization test (Fernandez et al., 1991). However, the IPMA test is not sensitive enough to detect acute infection, and therefore unsuitable for early diagnosis. With the advent of PCR, it was feasible to use in situ hybridization to diagnosis PRRSV by detecting expression using probes for ORF1b, ORF6, and ORF7 (Pirzadeh and Dea, 1998; Kwang et al., 1999). However, this method requires skilled, professional operators and expensive equipment. Finally, indirect immunofluorescence assays (IFA) were the first assays to detect PRRSV in pigs in China (Van Nieuwstadt et al., 1996). Immunohistochemical techniques have also been established to detect PRRSV infection in laboratory infected piglets (Meulenberg et al., 1997), but like in situ hybridization these assays are complex and require skilled staff. Thus, neither molecular nor immunodetection assays are suitable for rapid use on farms (Liu et al., 2001; Zhang et al., 2007, 2010; Akhter et al.,2017). Given the limits of current diagnostic assays, it is necessary to develop a rapid, sensitive, specific, and simple method of detecting PRRSV.

The RT-LAMP method has been successfully used to test for numerous pathogens in humans, livestock, poultry and aquatic animals. However, in clinical detection of swine, did not see the related application of LAMP method for detecting PRRSV. In this study, the primers for the RTLAMP assay was designed to target the ORF5 gene (TJM strain) that codes for the envelope glycoprotein E, which can induce cell apoptosis and is a target for neutralizing antibody in infected swine (Sur et al., 1998). As this assay requires all four primers to bind to the target DNA, the risk of non-specific amplification is very low. The RT-LAMP output could be visualized three ways; by agarose gel electrophoresis (laddered products), UV transillumination, or color change with the SYBR Green I dye (positive samples turned yellow-green). The multiple easy to read outputs products make RT-LAMP more convenient than RT-PCR. In this study, RT-LAMP was also approximately 100-fold more sensitive than RT-PCR and did not cross react with the other tested viruses. In addition, all five of 
the clinical samples tested yielded the same PRRSV results (+ or -) by RT-LAMP and RT-PCR. Given the sensitivity of the RT-LAMP assay, it is important to minimize potential contamination by separating the reaction and sample preparation areas.

\section{CONCLUSION}

In conclusion, the PRRSV RT-LAMP assay was rapid (60 min) and required minimal equipment (heating source). The assay was both faster and more sensitive than RT-PCR. Therefore, the RT-LAMP is a viable candidate for developing a rapid PRRSV detection kit for use in a clinical setting.

\section{ACKNOWLEDGEMENT}

We acknowledge the financial supports of the Sichuan Province Basic Research Program 2013JY0127, Key Laboratory of Ecological Security and Protection of Sichuan Province project ESP1505, Department of Education of Sichuan Province Project (16ZA0321), and the Mianyang Normal University Project QD2014A004/2015A02.

\section{Statement of conflict of interest}

The authors declare that there is no conflict of interests regarding the publication of this article.

\section{REFERENCES}

Akhter, H., Aslam, B., Shahzad, N., Farooq, T., Umer, M. and Rasool, M.H., 2017. Molecular and serological detection of avian influenza h9n2 virus in asymptomatic commercial layers in Faisalabad District, Punjab. Pakistan J. Zool., 49: 395-398. http://dx.doi.org/10.17582/journal. pjz/2017.49.1.sc6

Beura, L.K., Dinh, P.X., Osorio, F.A. and Pattnaik, A.K., 2011. Cellular poly(c) binding proteins 1 and 2 interact with porcine reproductive and respiratory syndrome virus nonstructural protein 1 beta and support viral replication. J. Virol., 85: 1293912949. https://doi.org/10.1128/JVI.05177-11

Bilodeau, R., Dea, S., Sauvageau, R.A. and Martineau, G.P., 1991. Porcine reproductive and respiratory syndrome in Quebec. Vet. Rec., 129: 102-103. https://doi.org/10.1136/vr.129.5.102

Cavanagh, D., 1997. Nidovirales: A new order comprising Coronaviridae and Arteriviridae. Arch. Virol., 142: 629-633.

Cho, J.G. and Dee, S.A., 2006. Porcine reproductive and respiratory syndrome virus. Theriogenology,
66: 655-662. https://doi.org/10.1016/j. theriogenology.2006.04.024

Fang, Y., Schneider, P., Zhang, W.P., Faaberg, K.S., Nelson, E.A. and Rowland, R.R., 2007. Diversity and evolution of a newly emerged North American Type 1 porcine arterivirus: Analysis of isolates collected between 1999 and 2004. Arch. Virol., 152: 1009-1017. https://doi.org/10.1007/s00705007-0936-y

Fernandez, A., Suarez, P., Castro, J.M. and Tabares, E., 1999. Characterization of the domains implicated in apoptosis induction by the PRRSV GP5 protein. Proceedings of the International Symposium on PRRS and Aujeszky's Disease, Ploufragan, France, June 21-24.

Kwang, J., Zuckermann, F., Ross, G., Yang, S., Osorio, F., Liu, W. and Low, S., 1999. Antibody and cellular immune responses of swine following immunisation with plasmid DNA encoding the PRRS virus ORF's 4, 5, 6 and 7. Res. Vet. Sci., 67: 199-201. https://doi.org/10.1053/rvsc.1998.0291

Li, Y., Wang, X., Bo, K., Wang, X., Tang, B., Yang, B., Jiang, W. and Jiang, P., 2007. Emergence of a highly pathogenic porcine reproductive and respiratory syndrome virus in the Mid-Eastern region of China. Vet. J., 174: 577-584. https://doi.org/10.1016/j. tvj1.2007.07.032

Liu, W.Q., Fan, Q.S., Jiang, Y., Xia, X.Z., Huang, G., Wang, J.G., Fang, J.B. and Wang, L., 2001. Establishment of a commonly used PCR technique for detection of carnivore parvoviruses. Chin. J. Vet. Sci., 21: 249-251.

Malele, I.I., Ouma, J.O., Enyaru, J.C., Matovu, E., Alibu, V., Auma, J.E., Onyoyo, S.G., Bateta, R., Changasi, R.E., Mukiria, P.W., Ndung'u, K., Gitonga, P.K., Mwaniki, L.M., Nyingilili, H.S., Lyaruu, E.A., Kapange, L.A., Kamau, P.K. and Masiga, D.K., 2013. Comparative diagnostic and analytical performance of PCR and LAMPbased trypanosome detection methods estimated using pooled whole tsetse flies and midguts. Vet. Parasitol., 197: 549-556. https://doi.org/10.1016/j. vetpar.2013.05.022

Maruyama, F., Kenzaka, T., Yamaguchi, N., Tani, K. and Nasu, M., 2003. Detection of bacteria carrying the stx2 gene by in situ loop-mediated isothermal amplification. Appl. environ. Microbiol., 69: 50235028. https://doi.org/10.1128/AEM.69.8.50235028.2003

Meulenberg, J.J., Petersen den Besten, A., de Kluyver, E., van Nieuwstadt, A., Wensvoort, G. and Moormann, R.J., 1997. Molecular characterization 
of Lelystad virus. Vet. Microbiol., 55: 197-202. https://doi.org/10.1016/S0378-1135(96)01335-1

Njiru, Z.K., 2012. Loop-mediated isothermal amplification technology: Towards point of care diagnostics. PLoS Negl. Trop. Dis., 6: e1572. https://doi.org/10.1371/journal.pntd.0001572

Notomi, T., Okayama, H., Masubuchi, H., Yonekawa, T., Watanabe, K., Amino, N. and Hase, T., 2000. Loop-mediated isothermal amplification of DNA. Nucl. Acids Res., 28: E63. https://doi.org/10.1093/ nar/28.12.e63

Pirzadeh, B. and Dea, S., 1998. Immune response in pigs vaccinated with plasmid DNA encoding ORF5 of porcine reproductive and respiratory syndrome virus. J. Gen. Virol., 79: 989-999. https://doi. org/10.1099/0022-1317-79-5-989

Snijder, E.J. and Meulenberg, J.J., 1998. The molecular biology of arteriviruses. J. Gen. Virol., 79: 961-979. https://doi.org/10.1099/0022-1317-79-5-961

Song, Q., Zhu, R., Sun, Y., Zhao, L., Wang, F., Deng, J. and Qian, Y., 2014. Identification of human metapneumovirus genotypes $\mathrm{A}$ and $\mathrm{B}$ from clinical specimens by reverse transcription loopmediated isothermal amplification. J. Virol. Methods, 196: 133-138. https://doi.org/10.1016/j. jviromet.2013.10.037

Sur, J.H., Doster, A.R. and Osorio, F.A., 1998. Apoptosis induced in vivo during acute infection by porcine reproductive and respiratory syndrome virus. Vet. Pathol., 35: 506-514. https://doi. org/10.1177/030098589803500605

Tian, K., Yu, X., Zhao, T., Feng, Y., Cao, Z., Wang, C., Hu, Y., Chen, X., Hu, D., Tian, X., Liu, D., Zhang,
S., Deng, X., Ding, Y., Yang, L., Zhang, Y., Xiao, H., Qiao, M., Wang, B., Hou, L., Wang, X., Yang, X., Kang, L., Sun, M., Jin, P., Wang, S., Kitamura, Y., Yan, J. and Gao, G.F., 2007. Emergence of fatal PRRSV variants: unparalleled outbreaks of atypical PRRS in China and molecular dissection of the unique hallmark. PLoS One, 2: e526. https:// doi.org/10.1371/journal.pone.0000526

Van Nieuwstadt, A.P., Meulenberg, J.J., van EssenZanbergen, A., Petersen-den Besten, A., Bende, R.J., Moormann, R.J. and Wensvoort, G., 1996. Proteins encoded by open reading frames 3 and 4 of the genome of Lelystad virus (Arteriviridae) are structural proteins of the virion. J. Virol., 70: 4767 4772.

Zhang, H.L., Yan, X.J., Chai, X.L. and Wu, W., 2007. Establishment and application of PCR for detection of mink enteritis virus. Spec. Wild Econ. Anim. Pl. Res., 34: 652-654.

Zhang, X., Liao, M., Jiao, P., Luo, K., Zhang, H., Ren, T., Zhang, G., Xu, C., Xin, C. and Cao, W., 2010. Development of a loop-mediated isothermal amplification assay for rapid detection of subgroup J avian leukosis virus. J. clin. Microbiol., 48: 21162121. https://doi.org/10.1128/JCM.02530-09

Zhao, X., Li, Y., Wang, L., You, L., Xu, Z., Li, L., He, X., Liu, Y., Wang, J. and Yang, L., 2010. Development and application of a loop-mediated isothermal amplification method on rapid detection Escherichia coli $\mathrm{O} 157$ strains from food samples. Mol. Biol. Rep., 37: 2183-2188. https://doi. org/10.1007/s11033-009-9700-6 